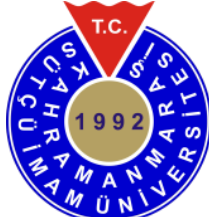 Kahramanmaras Sutcu Imam University Journal of Engineering Sciences
}

\section{İnsan Adım Yörünge Eğrilerinin 2R Manipülatör Kullanarak Elde Edilmesi}

\author{
Obtaining Human Step Trajectory Curves Using 2R Manipulator
}

\author{
Murat ÇATALKAYA ${ }^{1 *}$, Orhan Erdal AKAY ${ }^{1}$
}

${ }^{1}$ Kahramanmaraş Sütçü İmam Üniversitesi, Mühendislik-Mimarlık Fakültesi, Makine Mühendisliği Bölümü, Kahramanmaraş, Türkiye

*Sorumlu Yazar / Corresponding Author: Murat ÇATALKAYA, muradcatalkaya@gmail.com

\section{ÖZET}

Insansı robotların tasarım sürecinde, klasik yöntemler ile yürüme hareket denklemlerinin çıkarılması ve bu denklemlerin neticesinde yürüme uzuvlarını tahrik edecek büyüklüğün elde edilmesi oldukça zahmetli ve zaman isteyen bir süreçtir. İnsanın yürüyebilmesi için ayak uzvunu oluşturan her bir parçanın bir kas grubunu tahrik etmesi gerekmektedir Bu kas grupları yerine, robotlarda çeşitli aktüatörler ve mekanizmalar kullanılmaktadır. Bu nedenle tahrik elemanın seçimi oldukça önem taşımaktadır. Bu makale de $2 R$ manipülatör mekanizması insansı bir robot için bacak uzvu olarak kullanılmış ve yürüme yörüngesini veren parametrik konum eşitlikleri oluşturulmuştur. Ayrica bu eşitlikler içindeki bilinmeyen sabit katsayllar deneysel yürüme verileri kullanılarak çözülmüştür. Elde edilen matematiksel model ve verilerin çizdiği yörüngeler oldukça küçük bir hatayla elde edilmiştir.

Anahtar Kelimeler: Manipülatör, 2R Manipülatör, Working Model 2D,Yürüme Simülasyonu, Yürüme Yörüngesi, İnsans1 Robotlar

\section{ABSTRACT}

In the process of designing humanoid robots, it is a troublesome and time-consuming process to derive the walking motion equations with the classical methods and to obtain the magnitude to drive the walking links as a result of these equations. For a person to walk, each piece forming a foot should be driven by a muscle group. Instead of these muscle groups, robots use actuators and mechanisms. For this reason, the selection of the driving element is crucial. In this study, a humanoid robot has been used as a link with a $2 R$ manipulator mechanism and parametrical position equations giving the trajectory of walking have been obtained. In addition, unknown constant coefficients in these equations have been calculated from the experimental walking data. The trajectories of the mathematical model and the experimental data have been obtained with a very small error.

Keywords: Manipulator, 2R Manipulator, Working Model 2D, Walking Simulation, Walking Trajectory, Humanoid Robots

\section{GİRIŞ}

Son 20 yılda; elektrik, makine, bilgisayar, algılayıcılar ve otomatik kontrol alanlarındaki gelişmeler, robot ve robotik sistemlerin hızla gelişmesinin önünü açmıştır. Robotik konusundaki bu hızlı değişim, tarım, tıp, sanayi ve biyomekanik v.b. gibi farklı alanlarda, robotik sistemlerin kullanımını arttırmıştır. Robotik alanındaki diğer bir gelişme; önemli bir araştırma konusu halinegelmiş olan insansı robotlardır. İnsansı robotların temel avantajları; tekerlek, palet vb. hareket sistemlerine sahip robotlara göre, hareket yeteneklerinin sürekli olmayan ortamlarda daha yüksek olmasıdır (Sarıyıldız, 2016). İnsanın temel hareketlerinden olan yürüme ile ilgili pek çok çalışma yapılmış ve bu hareketin kinetik ve kinematik ayrıntıları birçok araştırmacı tarafından incelenmiştir (Nordin, 1999). İnsansı robotların ve insanların yürüyüş parametreleri birbirlerine oldukça benzerdir. Yürüyüş hareketi esnasında hem İnsansı robotların hemde insanların bir ayak uzvunun zemin ile temasta kalması zorunludur (Tez, 2017). Bundan dolayı, İnsansı robotun yürüyüş dengesi dinamiği oldukça karmaşık bir süreçtir. İnsansı robotların yürüyüş anında, bir ayak uzvunun zemin ile temasta kaldığı anda, dışarıdan etkiyen bozucu kuvvetler denge konumunu bozan önemli bir faktördür (Whittle, 2014). İnsansı robotların hareketini sağlayan bacak mekanizmaları, farklı zemin şekillerinde yürümesi için gerekli olan esnekliğe ve kontrolünü kolaylaştıran minimum sayıda tahrik elemanına sahip olacak şekilde tasarlanmaktadır (Shieh, 1996). Ayrıca bu tahrik hareketini veren aktuatörlerin de birbirleriyle uyum içinde çalışması gerekmektedir. Bu uyumu yakalayabilmek için her kas grubunu için kullanılan aktuatörlerin çalışma değerleri belirlenmelidir. İstenilen hareketi elde etmek için yürüme uzuvlarının matematiksel hareket modelinin elde edilmesi gerekmektedir (Çolak ve ark, 2002). Ancak bu denklemleri çözümlemek oldukça zor bir süreç olduğu için, bu süreçleri kolaylaştıran çeşitli analiz ve simülasyon yazılımları kullanılmaktadır. Son zamanlarda İnsansı robotlar üzerine yapılan çalışmalar içinde insan yürüyüşündeki doğal harmoniyi Honda firması yakalamıştır. Şirket Asimo isimli robotu ile doğal insan yürüyüşünü taklit etmeyi başarmıştır (Hirose ve ark, 2007). Doğadaki insan yürüyüşünü, bir mekanizma kullanarak elde etmek için yürüme analizi yapılır (Tez, 2017). Bu analizde kamera kullanılarak; kinematik yürüyüş verileri elde edilir (Özmanevra, 
2015). Bu çalışmada bir insana ait kinematik yürüyüş verileri kullanılarak, 2R manipulatör olarak tasarlanmış insan bacağını matematiksel modeli çözümlenmiştir.

\section{MATERYAL VE METOD}

\subsection{Materyal}

Bu çalışmanın ana materyali kinematik yürüme verilerinin elde edildiği insan bir deneğe ait yürüyüş modelidir. Yapılan yürüme analizinde; deneğin yürüyüş görüntüleri bir kamera yardımıyla kaydedilmiştir. Görüntünün analizi için, Tracker video çözümleyici programı kullanılmıştır. İnsan bacağı modelinin oluşturulması ve hareket simülasyonları Working Model 2D (WM2D) programında gerçekleştirilmiştir.

\subsection{Metod}

Bir insan adımı yürüyüş modelinin çizdiği yörüngeye ait verileri elde etmek için; yürüme platformu üzerinde $0,89 \mathrm{~m} / \mathrm{s}$ hız ve 3.2 sn süresi boyunca yürüyen bir deneğin yürüyüş görüntüsü kullanılmıştır. Deneğin yürüyüş görüntüsü,bir kamera tarafından avi formatinda kaydedilmiştir. Bu görüntü Tracker Programına aktarılarak, deneğin ayak bileğine ait yürüme eğrisinin verileri kartezyen koordinatlarda elde edilmiştir (Şekil 1).

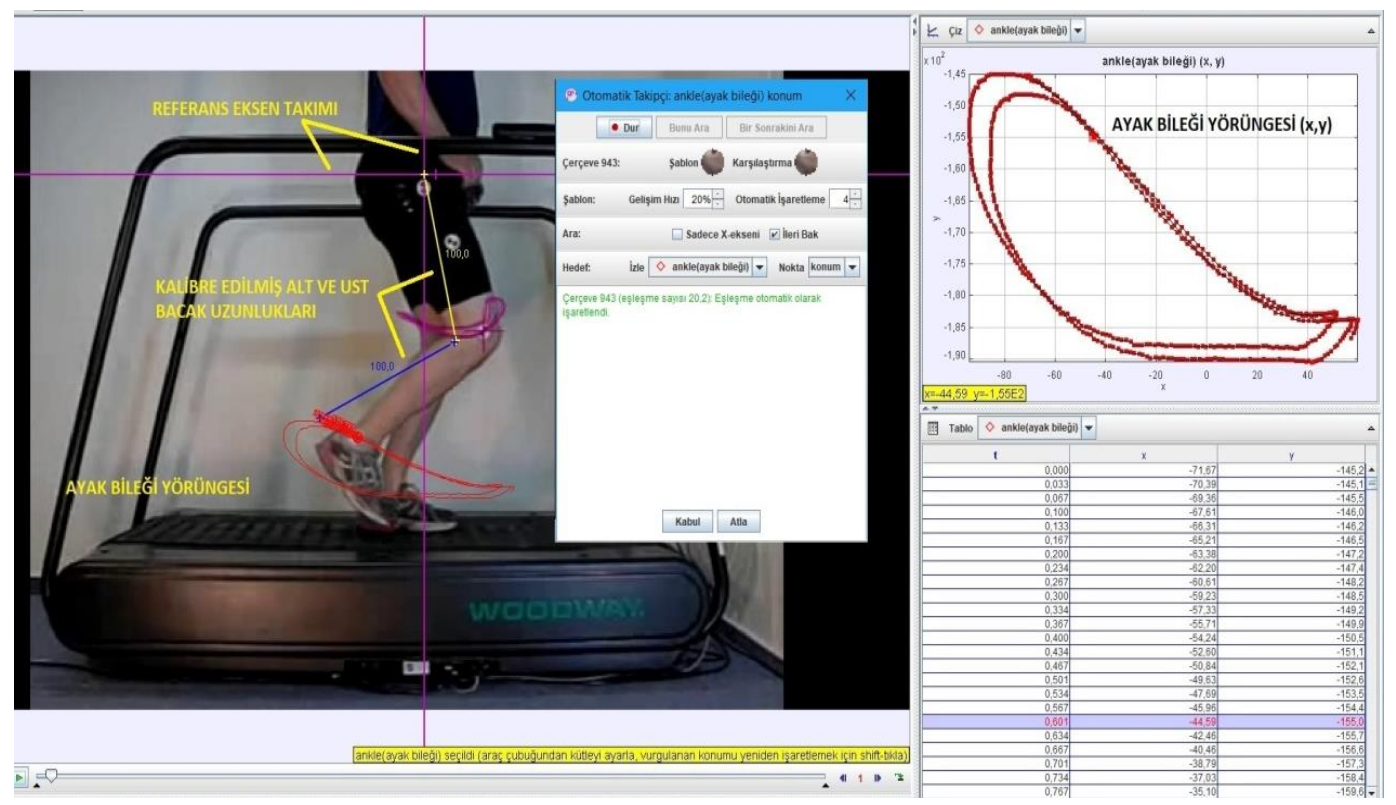

Şekil 1. Tracker Programında Yürüme Analizi Verileri

WM2D programında insan bacağ1 2R manipulator olarak tasarlanmıştır. Bu modelin hareketi için, kalça ve diz mafsallarına motor yerleştirilmiştir. Şekil 2 görüldügü üzere ; $2 \mathrm{R}$ manipülatörün uzuv uzunlukları $l_{1}=l_{2}=1$ birim olarak alınmıştır. $\theta_{10}=4.712$ ve $\theta_{20}=0$ radyan olmak üzere, $2 \mathrm{R}$ manipülatöre ait uzuvların başlangıç açılarıdır. Bu model ile Tracker programından aktarılan konum verileri kullanılarak mafsal açıları ölçülmüştür (Şekil 2). 


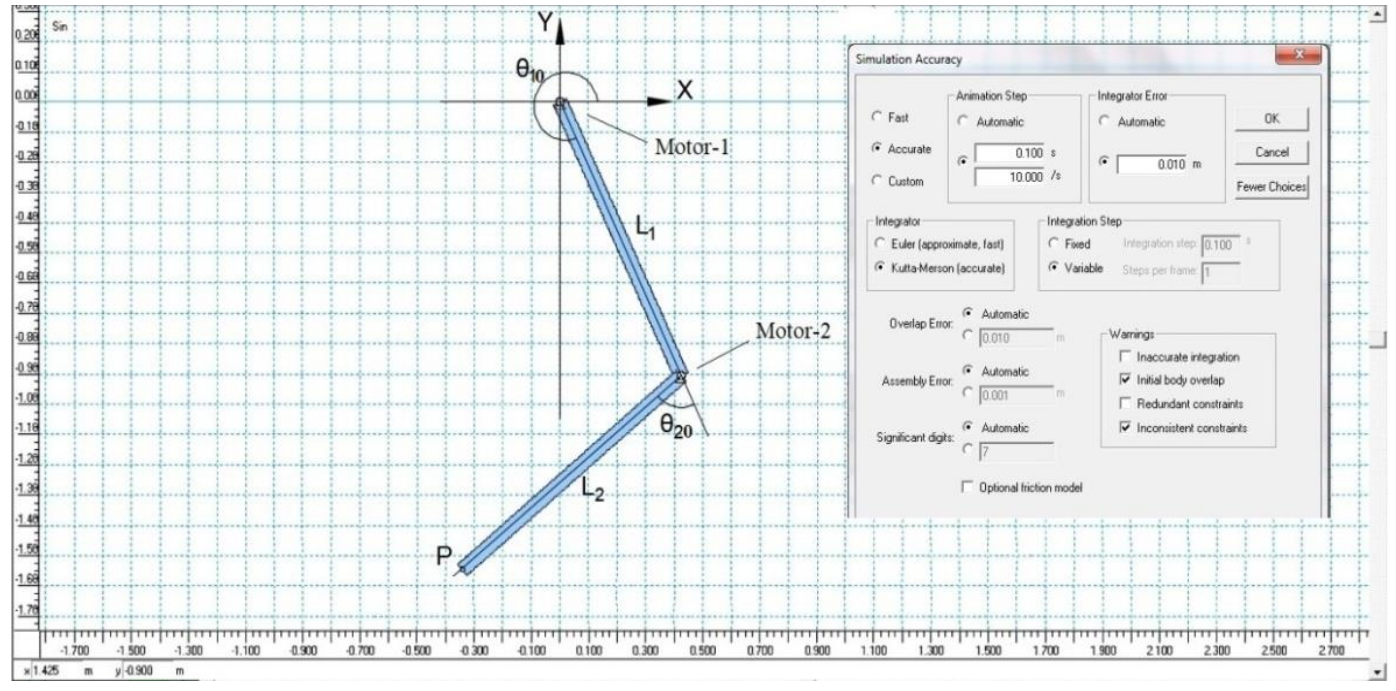

Şekil 2. 2R Manipulatör Bacak Modeli

Bu modelde; manipülatör uç efektörü olarak kabul edilen P noktasının kartezyen koordinatlarını veren eşitlikler (1-2) kullanılmıştır. $\mathrm{Bu}$ eşitliklerden, modelin parametrik denklemlerini elde etmek için yararlanılmıştır. Bu parametrik denklemlerde bilinmeyen, zamana bağlı açı değişimlerini veren matematiksel ifadelerin çözümü için eğri uydurma yöntemi uygulanmıştır. Bunun için Excel çözümleyici (Solver) aracı ile regresyon analizi yapılmıştır.

$$
\begin{aligned}
& x_{p}=l_{1} \operatorname{Cos} \theta_{10}+l_{2} \operatorname{Cos}\left(\theta_{10}+\theta_{20}\right) \\
& y_{p}=l_{1} \operatorname{Sin} \theta_{10}+l_{2} \operatorname{Sin}\left(\theta_{10}+\theta_{20}\right)
\end{aligned}
$$

\section{BULGULAR VE TARTIŞMALAR}

Deneğin bileğini temsil eden $\mathrm{P}\left(\mathrm{x}_{\mathrm{p}}, \mathrm{y}_{\mathrm{p}}\right)$ noktasının kartezyen koordinatlarını elde etmek için, denek yürüyüşü avi formatında kameraya çekilerek Tracker programına aktarılmıştır. Bu veriler WM2D üzerinde oluşturulan 2R bacak modeline aktarılarak, 2R bacak modelinin $\mathrm{P}\left(\mathrm{x}_{\mathrm{p}}, \mathrm{y}_{\mathrm{p}}\right)$ noktasının (ayak bileği) yörünge eğrisi (Şekil 3a) ve uzuvların zamana bağlı değişen eklem açılarına ait eğriler $\theta_{10}(t), \theta_{20}(t)$ elde edilmiştir (Şekil $\left.3 b\right)$.

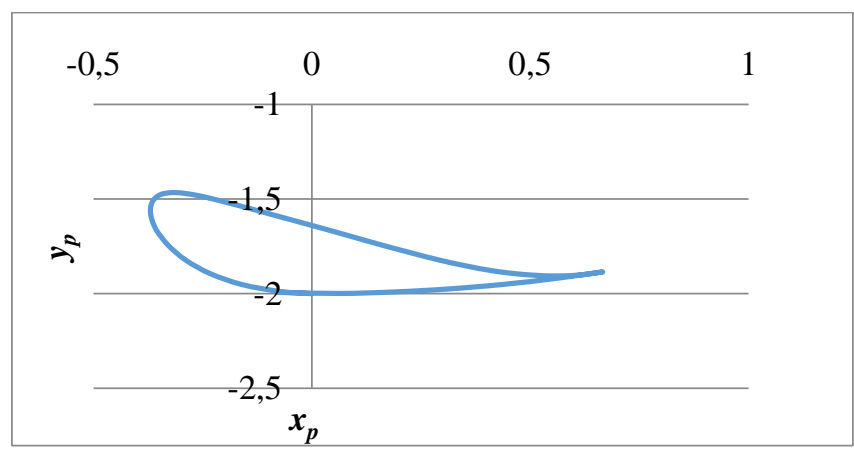

(a)

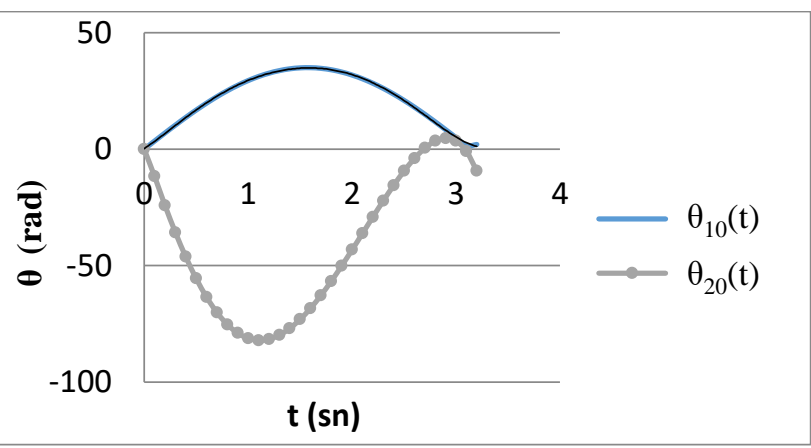

(b)

Şekil 3. 2R Bacak Modelinin Yörünge ve Açı Eğrileri

Eşitlik 1 ve 2; parametrik formda aşağıdaki gibi ifade edilebilir;

$$
\begin{aligned}
& x_{p}(t)=l_{1} \operatorname{Cos}\left(\theta_{10}+\theta_{1}(t)\right)+l_{2} \operatorname{Cos}\left[\theta_{10}+\theta_{20}+\theta_{10}(t)+\theta_{20}(t)\right] \\
& y_{p}(t)=l_{1} \operatorname{Sin}\left(\theta_{10}+\theta_{1}(t)\right)+l_{2} \operatorname{Sin}\left[\theta_{10}+\theta_{20}+\theta_{10}(t)+\theta_{20}(t)\right]
\end{aligned}
$$

$\mathrm{Bu}$ eşitliklerde, 2R modelinin uzuv açıları $\theta_{10}(\mathrm{t})$ ve $\theta_{20}(\mathrm{t})$ zamana bağlı değişmektedir. Bu açıları veren eşitlikler, zaman bağlı değişim şekline göre trigonometrik ve polinom formunda yazılabilir (Eşitlik 5-6).

$$
\begin{aligned}
& \theta_{10}(t)=A / \operatorname{Sin}(B t+\emptyset) \\
& \theta_{20}(t)=a_{0}+a_{1} t+a_{2} t^{2}+a_{3} t^{3}+a_{4} t^{4}+a_{5} t^{5}+a_{6} t^{6}+a_{7} t^{7}+a_{8} t^{8}
\end{aligned}
$$


$\mathrm{Bu}$ eşitliklerdeki bilinmeyen sabit katsayıları belirlemek için Şekil 3 grafiklerini oluşturan veriler kullanılmış ve eğri uydurma (Curve Fitting) yöntemi uygulanmıştır. Regresyon analizinde, yineleme adım sayısı olarak 100, duyarlık 0,000001, yakınsama 0,0001 seçilmiş ve analiz sonucu her iki analizin sonucu olarak $\mathrm{R}^{2}=0.999$ bulunmuştur. Regresyon sonuçları Çizelge 1'de verilmiştir.

Çizelge 1. Regresyon Sonuçları

\begin{tabular}{cc}
\hline $\mathrm{a}_{0}$ & 1.556 \\
$\mathrm{a}_{1}$ & -135.84 \\
$\mathrm{a}_{2}$ & 31.821 \\
$\mathrm{a}_{3}$ & 20.241 \\
$\mathrm{a}_{4}$ & 13.089 \\
$\mathrm{a}_{5}$ & -16.937 \\
$\mathrm{a}_{6}$ & 5.447 \\
$\mathrm{a}_{7}$ & -0.612 \\
$\mathrm{~A}$ & 35 \\
$\mathrm{~B}$ & 1 \\
$\varnothing$ & 0 \\
\hline
\end{tabular}

(3) ve (4) numaralı eşitlikler, regresyon sonuçlarına göre düzenlenmiş ve bu eşitlikler kullanılarak 2R manipülatöre ait yörünge eğrileri çizilmiştir (Şekil 4).

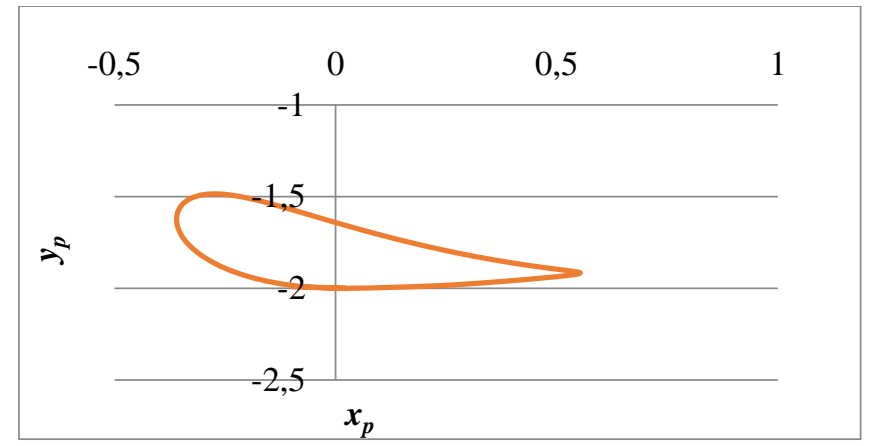

Şekil 4. 2R Manipülatör $\mathrm{P}\left(\mathrm{x}_{\mathrm{p}}, \mathrm{y}_{\mathrm{p}}\right)$ Noktasının Yörünge Eğrisi

\section{SONUÇLAR}

Bu çalışma üç temel aşama ile oluşturulmuştur. Bir deneğe ait yürüme videosu kullanılarak yürüme eğrisi elde edilmiş, bu veriler WM2D hareket simülasyon programında oluşturulan 2R bacak modeline aktarılarak, deneysel verilerden elde edilemeyen zamana bağlı açı değişimleri elde edilmiştir. Açı değişim verileri, deneğin yürüyüş hareketini 2R manipülatör kullanarak tanımlamak amacıyla oluşturulmuş parametrik denklem takımındaki bilinmeyen sabit katsayıların çözümü için kullanılmış ve modelin başarısını gösteren $\mathrm{R}^{2}$ değeri 0.999 bulunmuştur. Deneğin bileğini temsil eden $\mathrm{P}\left(\mathrm{x}_{\mathrm{p}}, \mathrm{y}_{\mathrm{p}}\right)$ noktasının kartezyen koordinatlarının oluştırduğu eğri ile 2R manipülatör uç efektörü olan $\mathrm{P}$ noktasının kartezyen koordinatlarını veren eşitlik (3) ve (4) ile elde edilmiştir. Deneysel ve hesap yoluyla elde edilen yürüme yörüngeleri Şekil 5'de verilmiştir.

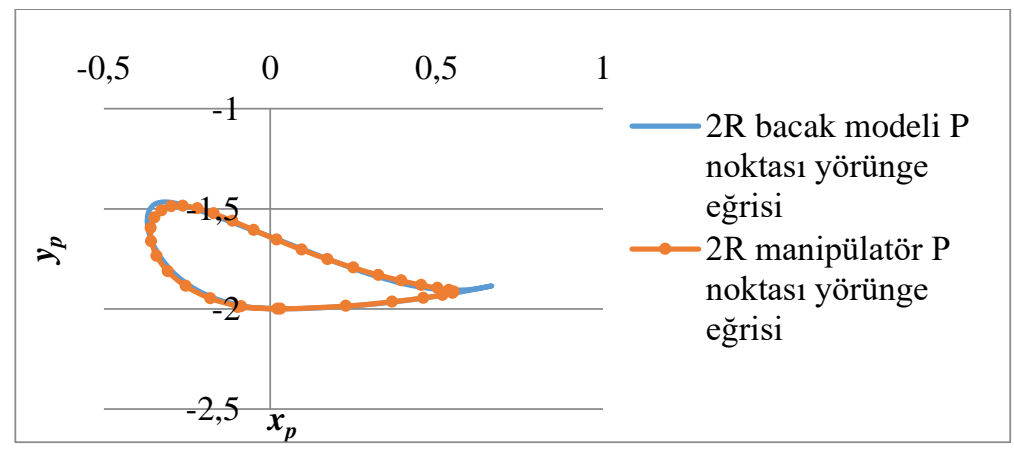

Şekil 5. 2R Manipülatör ve 2R Bacak Modeli $P\left(x_{p}, y_{p}\right)$ Noktasının Yörünge Eğrisi 
Son olarak kulllanılan deneysel adım verileri ve manipülatöre ait matematiksel eşitlikler kulllanılarak WM2D programında iki özdeş 2R modeli ile hareket simülasyonları gerçekleştirilmiş ve özdeş iki yörünge eğrisi elde edilmiştir. Bunun için eşitlik (5) ve (6) 2R manipülatöre ait 1 ve 2 numaralı motorlara uygulanmıştır (Şekil 6).

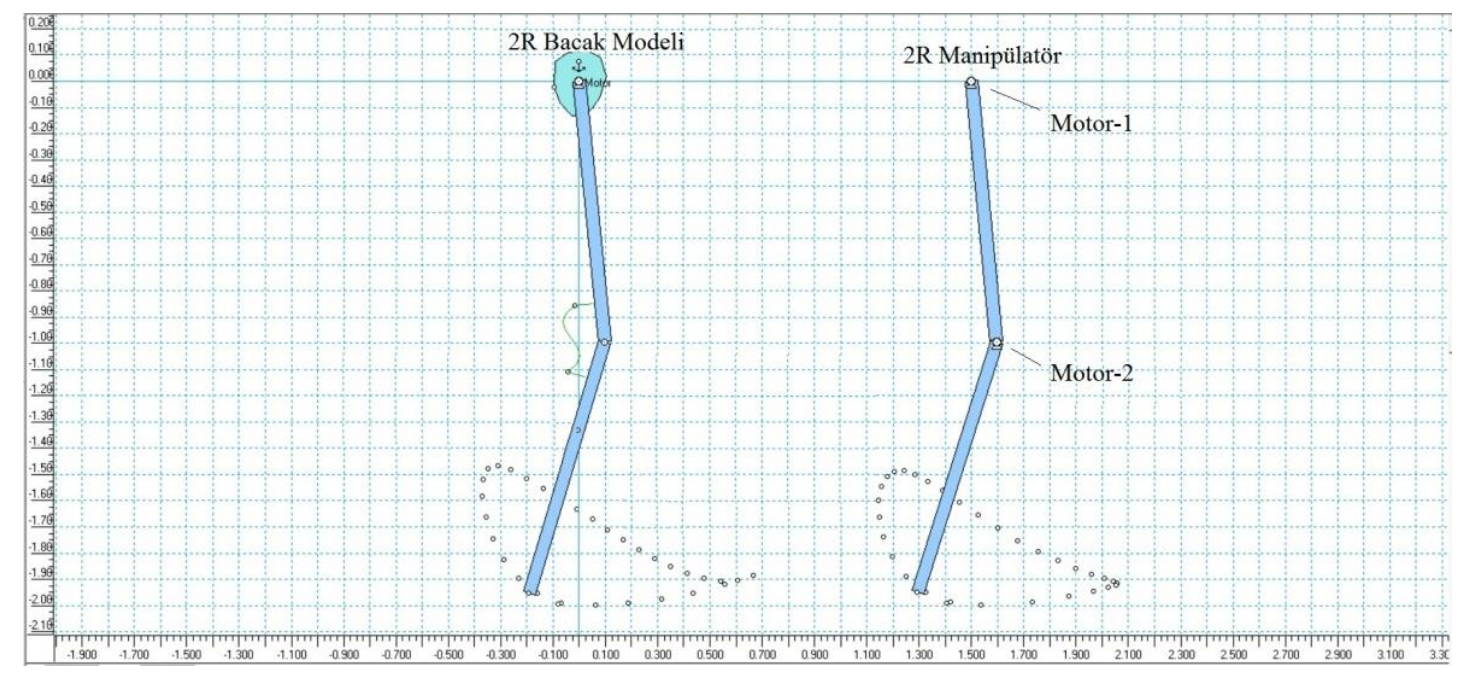

Şekil 6. 2R Manipülatör ve 2R Bacak Modeli WM2D deki P Yörünge Eğrileri

\section{KAYNAKLAR}

Çolak, M, Mermertaş, V. (2003), Mekanizmalarda Yörünge Sentezi, Yüksek Lisans Tezi, Makine Mühendisliği, İstanbul Teknik Üniversitesi, İstanbul.

Hirose, M., Ogawa K. (2007), Honda humanoid robots development. Philosophical Transactions of the Royal Society of London A: Mathematical, Physical and Engineering Sciences. 365(1850): p. 11-19.

Nordin, M., Ozkaya N, (1999), Fundamentals of Biomechanics: Equilibrium, Motion, and Deformation, Springer-Verlag, New York.

Özmanevra, R. (2015), Farklı Materyal Kullanılarak Yapılan Tabanlıkların Yürümenin Kinetik ve Kinematik Özellikleri Üzerine Etkilerinin Araştırılması, Uzmanlık Tezi, Tıp Fakültesi, Ortopedi ve Travmatoloji Anabilim Dalı, Dokuz Eylül Üniversitesi, İzmir.

Sarıyıldız, E. (2016), İnsansı Robotların Tüm Vücut Kinematik ve Dinamik Modellenmesi ve Kontrolu, Doktor Tezi, Kontrol ve Otomasyon Mühendisliği, İstanbul Teknik Üniversitesi, İstanbul.

Shieh, W.B. (1996), Design and Optimization of Planar Leg Mechanisms Featuring Symmetrical Foot-Point Paths, Doctor of Philosophy, Department of Mechanical Engineering, University of Maryland, Maryland.

Tez, T. (2017), İki Ayaklı Yürüyen Robot Dinamiğinin Deneysel ve Teorik Araştırılması, Doktor Tezi, Makine Mühendisliği, Trakya Üniversitesi, Edirne.

Whittle, M.W. (2014), Gait analysis: an introduction, Butterworth-Heinemann, Oxford, UK. 